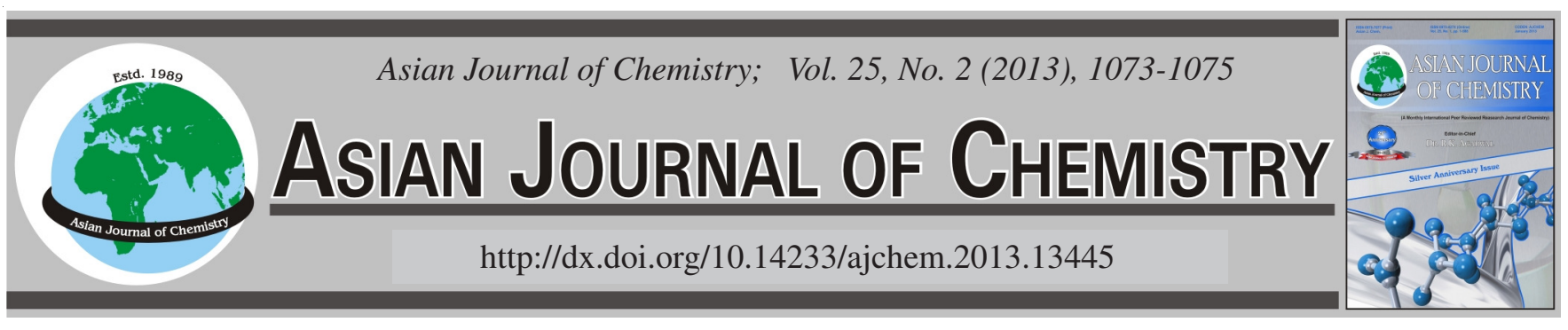

\title{
Study on Producing Hydrogen by Catalytic Pyrolysis of Coal Slime
}

\author{
LeI ZhanG ${ }^{1}$, HaO WANG ${ }^{2}$ and XINQIAN $\mathrm{SHU}^{3, *}$
}

${ }^{1}$ School of Geology and Environment, Xi'an University of Science and Technology, Xi'an 710054, P.R. China

${ }^{2}$ College of Civil and Architecture Engineering, Hebei United University, Tangshan, P.R. China

${ }^{3}$ School of Chemical and Environmental Engineering, China University of Mining and Technology, Beijing 100083, P.R. China

*Corresponding author: E-mail: shuxinqian@126.com

\begin{abstract}
This paper mainly focused on the law of flammable hydrogen-rich gas by coal slime pyrolysis. In order to increase the production of hydrogen, this experiment added different $n$-type metal-oxide and alkali metal oxide as catalyst in the process of pyrolysis. It provided an effective and reliable method of clean and efficient utilization of coal slime. Experiments showed that the catalytic activity was very low from room temperature to $600{ }^{\circ} \mathrm{C}$, no matter added catalyst or not the yield of hydrogen was very little. But in high-temperature range (600-1 $100^{\circ} \mathrm{C}$ ), catalyst showed different catalytic effect. In $600-800^{\circ} \mathrm{C}$ temperature region, $\mathrm{CaO}$ showed the strongest catalytic effect. It is not only to increase the yield and output of hydrogen, but also plays a significant role to improve the yield of $\mathrm{CO}$, the yield of the $\mathrm{CO}$ could increased from 3.85 to $21.24 \%$. In the high temperature range of $800-1100{ }^{\circ} \mathrm{C}, n$-type semiconductor catalyst shown a good catalytic effect, especially $\mathrm{Fe}_{2} \mathrm{O}_{3}$ catalyst increased the yield of hydrogen from 56.51 to $82.06 \%$ at $1100{ }^{\circ} \mathrm{C}$, the total output can also increase twice.
\end{abstract}

Key Words: Coal slime, Catalytic pyrolysis, Hydrogen, Catalyst.

\section{INTRODUCTION}

Coal slime quantity increased rapidly, in China with development of coal preparation industry. If the coal slime could not be controlled, it caused not only severe environmental pollution but also wasting energy seriously ${ }^{1-3}$. The current utilization methods of coal slime focused on pressing filtration recovery and combustion technology, the economic benefit is relatively low $^{4-10}$. Therefore, use of coal slime is increasingly stressed on producing useful materials ${ }^{11-13}$. The main component of coal slime is carbon, the pyrolysis processes of coal slime obey the laws of coal pyrolysis. The products of coal slime pyrolysis included gas, tar and semi-coke. The gas contains a large number of $\mathrm{H}_{2}, \mathrm{CO}, \mathrm{CH}_{4}$ and other flammable gas, coal slime could be used as important raw materials to product high calorific value gas ${ }^{14-16}$.

In this paper, the purpose is to find a high efficient catalyst of coal slime pyrolysis to ensure its high hydrogen productivity, at same time minimizing the temperature of pyrolysis, improving the yield of hydrogen, raising the total coal slime conversion of and reducing coal slime pyrolysis costs.

\section{EXPERIMENTAL}

The schematic of the experiment system is shown in Fig. 1. In this experiment, samples are placed in the constant tempe- rature area of the furnace a programmed heating pyrolysis tubular. The indoor temperature of the furnace is increased from room temperature to $1100^{\circ} \mathrm{C}$ with a heating rate of $15^{\circ} \mathrm{C}$ $\mathrm{min}^{-1}$. The reaction takes $1 \mathrm{~h}$. Pyrolysis gas is collected and analyzed by gas chromatography after going through the dedusting equipment and drying devices at the increase of every $100{ }^{\circ} \mathrm{C}$. The gas chromatography is SP2100, the hydrogen concentration was analyzed by nitrogen as carrier and the carbon dioxide and carbon monoxide concentration was analyzed by helium as carrier, using the formula $\mathrm{V}=\mathrm{c} \times \mathrm{v}$ to calculate the gas yield. $\mathrm{V}$ is gas yield $(\mathrm{mL})$, $\mathrm{c}$ is gas concentration by gas chromatography; $\mathrm{v}$ is gas volume $(\mathrm{mL})$. The experimental device is shown in Fig. 1.

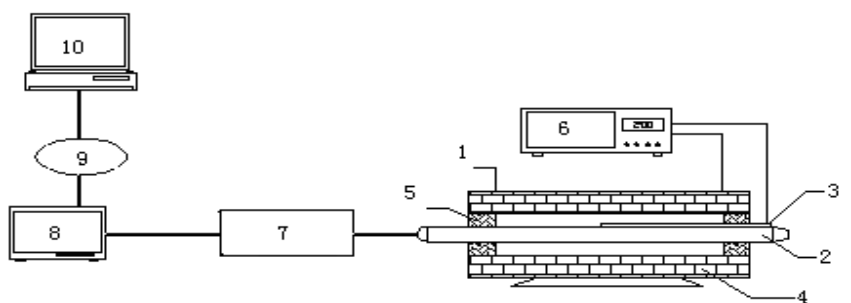

1. Pyrolysis furnace, 2. Reactor, 3. Thermocouple, 4. Refractory lining,

5. Fire-resistant cotton, 6. Temperature control devices, 7. Condensing and purification devices, 8. Flow gauge, 9. Gas collection devices, 10. GC

Fig. 1. Fixed bed reactor and diagram of pyrolysis equipment 
The coal slime used for this study was taken from concentrated bottom flow in Zhao Zhuang coal preparation plant. Under linear temperature increase condition, the temperature increased from room temperature to $1100{ }^{\circ} \mathrm{C}$. The process of coal slime pyrolysis was mainly dehydration and removal of volatile until $600^{\circ} \mathrm{C}$, the gas yield was less at this stage, the effect adding catalysts is not obvious. So the gas collection start from $600^{\circ} \mathrm{C}$ and set up a sampling each interval of $100^{\circ} \mathrm{C}$. Pyrolysis time was $70 \mathrm{~min}$, heating rate was about $100^{\circ} \mathrm{C} / 6 \mathrm{~min}$. Finally, the collected gas will be analysis by gas chromato-graphy.

Catalyst selection: The catalyst includes $n$-type semiconductor metal-oxide $\left(\mathrm{TiO}_{2}, \mathrm{Fe}_{2} \mathrm{O}_{3}, \mathrm{CuO}\right.$ and $\left.\mathrm{MoO}_{3}\right)$ and alkali metal oxide $(\mathrm{CaO})$. Metal oxides were commercial products. In all experiments, the dosage of coal slime is $30 \mathrm{~g}$; the mass ratio of catalyst is $2 \%$.

\section{RESULTS AND DISCUSSION}

The pyrolysis of coal slime can be divided into three stages under linear temperature increase condition: the first stage was from room temperature to $300{ }^{\circ} \mathrm{C}$, it played the role of dehydration degassing mainly. The second stage was from 300$500{ }^{\circ} \mathrm{C}$, in this stage dry coal slime was made of semi-coke and released polymer organic hydrocarbon material substances, namely coal tar. The third stage was from $500-950{ }^{\circ} \mathrm{C}$, this stage was the key of reaction. the main reaction generated coke and a large number of $\mathrm{H}_{2}, \mathrm{CH}_{4}$ and other low molecular weight gas. The peak period of the hydrogen production appeared after $800^{\circ} \mathrm{C}$.

The Figs. 2-5 shows the effect of different catalysis temperature on hydrogen yield and output. From Figs. 2 and 4 we can seen that the yield and output of hydrogen have been impacted by adding catalyst in $600-1000^{\circ} \mathrm{C}$. In $600-800^{\circ} \mathrm{C}, \mathrm{CaO}$ obtained clear effect, the yield and output of hydrogen had increased significantly, next came $n$-type semiconductor metaloxide $\left(\mathrm{MoO}_{3}, \mathrm{Fe}_{2} \mathrm{O}_{3}, \mathrm{TiO}_{2}\right.$ and $\left.\mathrm{CuO}\right)$. In $800{ }^{\circ} \mathrm{C}-1100{ }^{\circ} \mathrm{C}, n$ type semiconductor catalyst showed significant catalytic effect, especially adding $\mathrm{Fe}_{2} \mathrm{O}_{3}$ as catalyst in $1100^{\circ} \mathrm{C}$ the hydrogen yield increased from 56.51 to $82.06 \%$, total hydrogen yield increased more than one time. The main reason was due to the $\mathrm{MoO}_{3}, \mathrm{Fe}_{2} \mathrm{O}_{3}, \mathrm{TiO}_{2}$ and $\mathrm{CuO}$ were $n$-type metal oxide semiconductor with variable valence, because of gaseous hydrocarbons generated in $600-1000{ }^{\circ} \mathrm{C}$, olefins occured chemical adsorption on the surface of metal oxide, Olefin is absorbed on the surface of metal positive ion as electron donor $^{13,14}$ (eqns. 1 and 2).

$$
\begin{gathered}
\mathrm{C}_{\mathrm{n}} \mathrm{H}_{2 \mathrm{n}}-2 \mathrm{e} \rightarrow \mathrm{C}_{\mathrm{n}} \mathrm{H}_{2 \mathrm{n}-2}+2 \mathrm{H}^{+} \\
2 \mathrm{H}^{+}+2 \mathrm{e} \rightarrow \mathrm{H}_{2}
\end{gathered}
$$

Eqn. 2 is the reaction controlling step. This reaction is removed electronics from the catalyst. Actually it is the molecular desorption process of $\mathrm{H}^{+}$became $\mathrm{H}_{2}$ on catalyst surface. Because of electron donor gas absorbed in the $n$-type semiconductor, it made the work function reduced, electrical conductivity enhanced and surface charge increased. So that $n$-type semiconductor catalyst could provide more electronic, it is in favour of the reaction 2, $n$-type semiconductor is conducive to producing hydrogen.

Calcium oxide was the representative solid basic catalyst, the basic catalyst was conducive to the coal pyrolysis in the

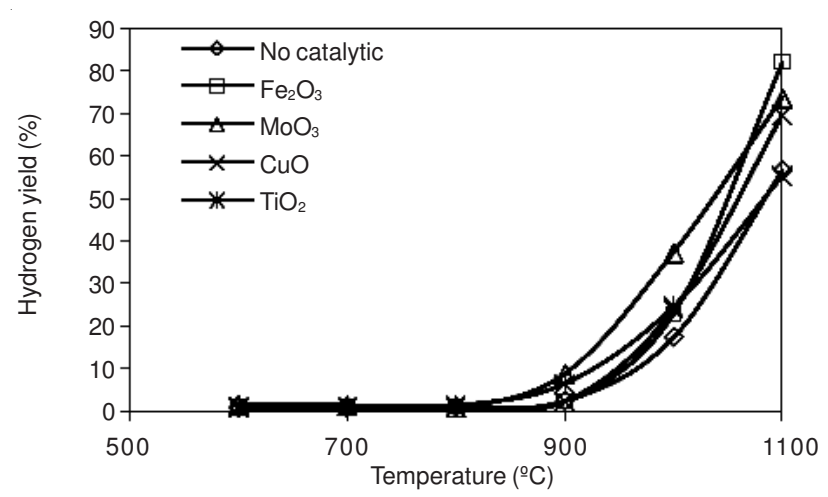

Fig. 2. Relation of temperature and hydrogen yield in different $n$-type metal-oxide

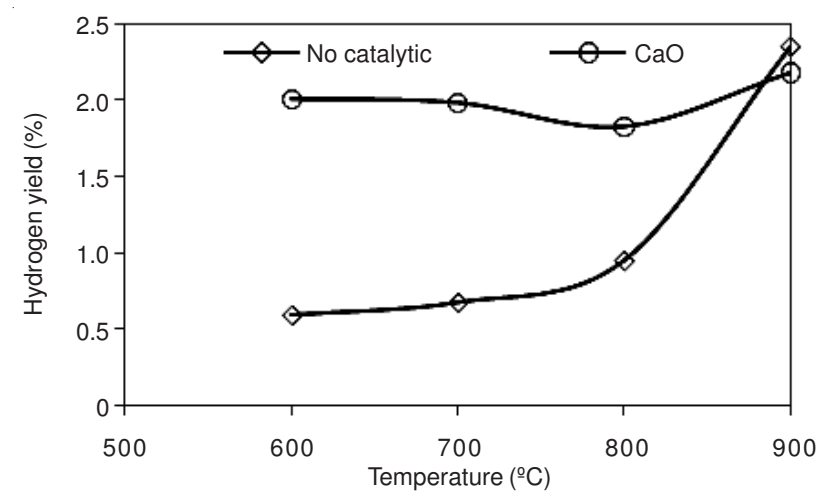

Fig. 3. Relation of temperature and hydrogen yield in alkali metal oxide catalyst

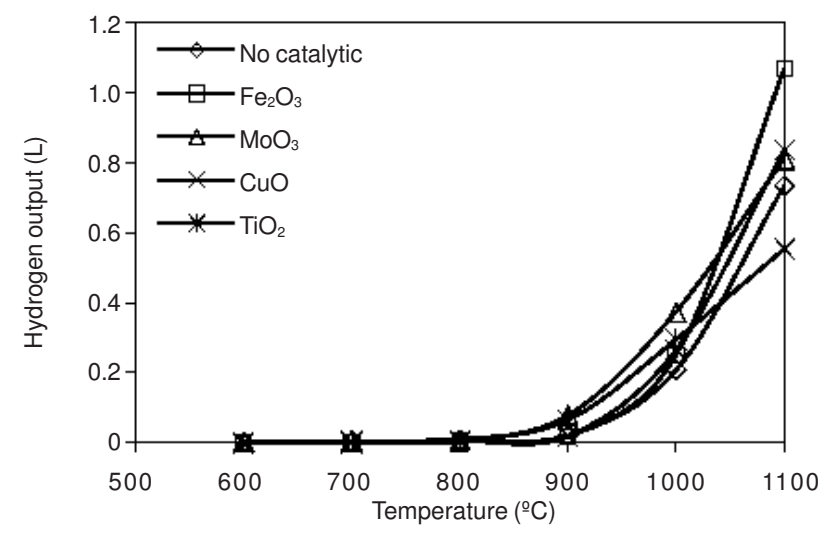

Fig. 4. Relation of temperature and hydrogen output in different $n$-type metal-oxide catalyst

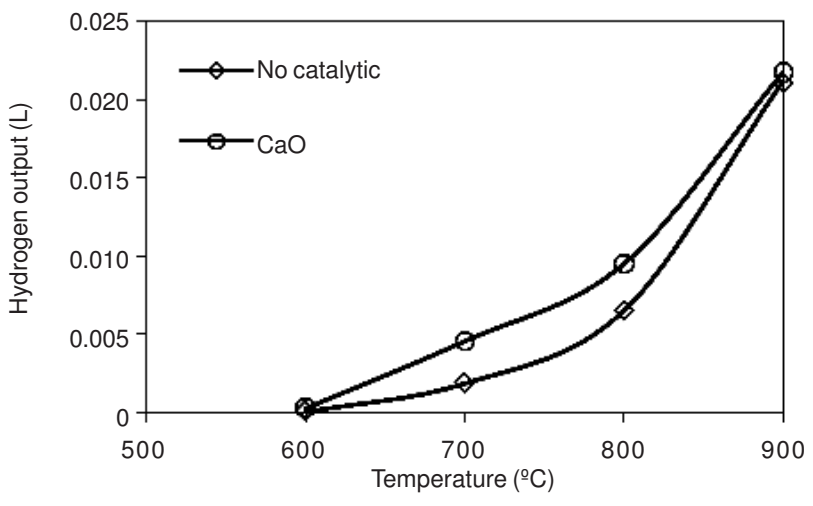

Fig. 5. Relation of temperature and hydrogen output in alkali metal oxide catalyst 
medium temperature (Figs. 3, 5 and 6). The basic catalyst had catalysis on olefinic polymerization and aldol condensation. The activation of alkanes and olefins were completed by position carbanion formation with basic catalysis. The base sites of basic catalysis reaction could provide electron pair which can remove the $\mathrm{H}^{+}$from $\mathrm{C}-\mathrm{H}$. However, we also found (Fig. 6), the activity of $\mathrm{CaO}$ showed decreasing trend with increasing temperature, the reason may be that the yield of carbon dioxide and coke increased drastically in high-temperature phase, the response is as follows:

$$
\begin{gathered}
\mathrm{Ca}_{\mathrm{n}} \mathrm{O}_{\mathrm{m}}+\mathrm{CO}_{2} \rightarrow \mathrm{Ca}_{\mathrm{n}} \mathrm{O}_{\mathrm{m}+2}+\mathrm{C} \\
\mathrm{Ca}_{\mathrm{n}} \mathrm{O}_{\mathrm{m}+2}+\mathrm{C} \rightarrow \mathrm{Ca}_{\mathrm{n}} \mathrm{O}_{\mathrm{m}}+\mathrm{CO}
\end{gathered}
$$

Fig. 6 showed that the yield of $\mathrm{CO}$ increased from 3.85 to $21.24 \%$ when added $\mathrm{CaO}$ catalyst, the results can be further proof of the above assumptions. The activity dehydrogenation of added $\mathrm{CaO}$ catalyst decreased in the high temperature, but $\mathrm{CO}$ production increased.

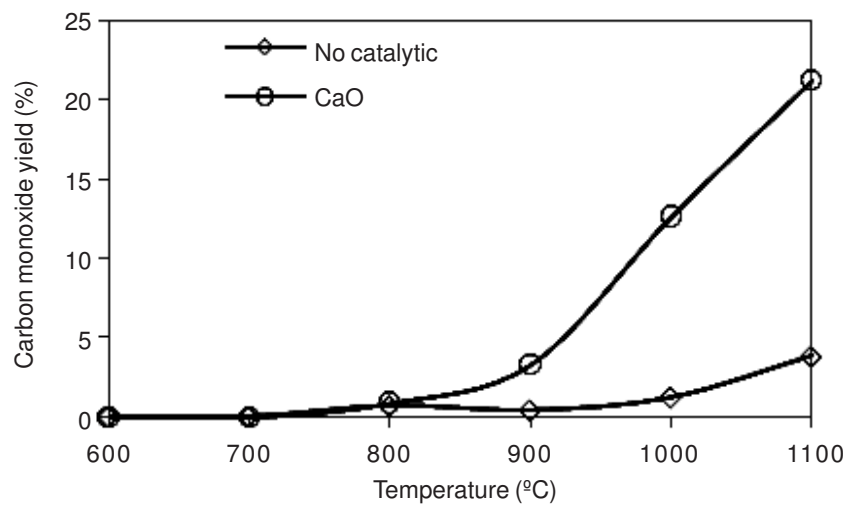

Fig. 6. Relation of temperature and carbon monoxide yield in alkali metal oxide catalyst

\section{Conclusion}

Catalysts had obvious influence on producing hydrogen from coal slime pyrolysis. In $600-800{ }^{\circ} \mathrm{C}, \mathrm{CaO}$ shown the strongest catalytic effect, it is not only to increase the yield and output of hydrogen, but also plays a significant role to improve the yield of $\mathrm{CO}$. In the high temperature range of 800-1100 ${ }^{\circ} \mathrm{C}, n$-type semiconductor catalyst shown a good catalytic effect, especially $\mathrm{Fe}_{2} \mathrm{O}_{3}$ catalyst increased the yield of hydrogen from 56.51 to $82.06 \%$ at $1100{ }^{\circ} \mathrm{C}$, the total output can also increase twice. The different $n$-type oxides had different catalytic activity was mainly due to its intrinsic properties such as crystal texture, local coordinative environments, semiconductor characterization and different acidity and alkaline.

\section{ACKNOWLEDGEMENTS}

The financial support of this research by Natural Science Basic Research Plan in Shaanxi Province of China (Program No. 2011JQ2015) in P.R. China is gratefully acknowledged.

\section{REFERENCES}

1. L. Li and Y.S. Pei, Shanxi Energy Conserv., 1, 36 (2001).

2. T.V. Choudhary, C. Sivadinarayana, C.C. Chusuei, A. Klinghoffer and D.W. Goodman, J. Catal., 199, 9 (2001).

3. S. Naresh, P. Devadas and P.H. Gerald, Energy Fuels, 15, 1528 (2001).

4. J.D. Zhu, S.Q. Zhu and G.W. Cui, Coal Prep. Technol., 4, 69 (2004).

5. D.Z. Wang, J. China Coal, 25, 9 (1999).

6. Y.F. Li, Coal Sci. Technol., 30, 32 (2002).

7. B. Xiao, J.F. Jiang, J.K. Yang, J.F. Li and X.Y. Shi, Fresenius Environ. Bull., 15, 314 (2006).

8. H.Z. Cheng, X.F. Chang and X. Gu, Coal Prep. Technol., 6, 55 (2003).

9. H.K. Abdel-aal, M.A. Shalabi, D.K. Al-Harbi and T. Hakeem, Int. J. Hydrogen Energy, 23, 457 (1998).

10. G.J. Conibeer and B.S. Richards, Int. J. Hydrogen Energy, 32, 2703 (2007).

11. M.A. Rosen and D.S. Scott, Int. J. Hydrogen Energy, 17, 199 (1992).

12. K.C. Xie, Y.K. Lu, Y.J. Tian and D.-Z. Wang, Energy Sour., 24, 1093 (2002).

13. Zhan Chuanxin, Shu Xinqian, Zhang Lei, et al., Coal Prep. Technol., 3, 7 (2007).

14. C.X. Zhan, X.Q. Shu and S.L. Song, J. China Coal, 33, 57 (2007).

15. T. Rampe, A. Heinzel and B. Vogel, J. Power Sour, 86, 536 (2000).

16. G. Skodras, P. Grammelis and P. Basinas, Bioresour. Technol., 98, 1 (2007). 